\title{
Erratum to: Towards Digital Optical Networks
}

\author{
Ioannis Tomkos ${ }^{1}$, Maria Spyropoulou ${ }^{1}$, Karin Ennser ${ }^{2}$, Martin Köhn ${ }^{3}$, \\ and Branko Mikac ${ }^{4}$ \\ 1 Athens Information Technology Centre, 19002 Peania-Attica, Greece \\ \{itom,mspi\}@ait.edu.gr \\ 2 Swansea University, Institute of Advanced Telecommunications, \\ SA2 8PP, Swansea, UK \\ k.ennser@swansea.ac.uk \\ 3 University of Stuttgart, IKR, 70569 Stuttgart, Germany \\ martin.koehn@ikr.uni-stuttgart.de \\ 4 University of Zagreb, \\ Faculty of Electrical Engineering and Computing (FER), \\ Department of Telecommunications, 10000 Zagreb, Croatia \\ branko.mikac@fer.hr
}

\section{Erratum to: \\ I. Tomkos et al. (Eds.) \\ Towards Digital Optical Networks \\ DOI: $10.1007 / 978-3-642-01524-3$}

The book was inadvertently published with an incorrect name of the copyright holder. The name of the copyright holder for this book is: (c) Springer-Verlag Berlin Heidelberg. The book has been updated with the changes.

The updated original online version for this book can be found at DOI: 10.1007/978-3-642-01524-3

I. Tomkos et al. (Eds.): COST 291 - Towards Digital Optical Networks, LNCS 5412, p. E1, 2009.

(C) Springer-Verlag Berlin Heidelberg 2017 